\section{MEDICINE IN DACHAU*}

BY

\section{HENRI ROSENCHER, M.D.}

Of 293,000 French people deported to Germany 42,000 came back, and $65 \%$ of these were found to be in bad health on their arrival in France. In this article, the medical aspects of life in a concentration camp are described, the facts being taken from Dachau, where I spent 8 months. The subject is, considered under four headings-hygiene, morbidity factors, medical organization, and the pathology of the internee, the part played by starvation and overcrowding being emphasized, with a final note on the commonest sequelae of life in the camp as shown by a follow-up of 1,000 cases in the Department of the Seine.

\section{Hygiene}

At first glance Dachau would appear to be a model camp. The visitor (assuming that his entry were possible) would b: impressed by the football ground, the clothing stores full of garments, the fine shower-baths with their modern heating installation, the spotless kitchens, and the charming lay-out of the buildings with flower-beds and an avenue of poplars. The Revier (sick-bay) would seem amazingly clean and tidy. It included rooms for eye and E.N.T. clinics, a physiotherapy room with the most modern apparatus (even an electrocardiograph), a big dressing-station, two magnificent operating theatres with a sterilization room, an $x$-ray department, a dental clinic, a well-fitted laboratory, a well-stocked dispensary, and beautiful parquet floors to the wards. If, further, the medical routine of the camp were described-the bath and disinfestation on entry, the initial medical examination complete with radiography, the insistence on daily hygiene, the regular routine examinations and the formidable total of medical personnel in the camp-the visitor could not but marvel at the German genius for organization.

But the inmate saw a very different aspect. On arrival he was stripped of all he possessed, shaved all over, and conscientiously rubbed with a carbolic solution so strong that it frequently caused severe burns. The shower might be boiling or ice-cold, and was followed by many hours of waiting, naked, hungry, and cold, for an issue of camp clothing. The entire operation was repeated almost monthly, when all clothing was sent for an alleged disinfestation in an apparatus the maximum temperature of which was admirably suited to the further develop ment of the nit, and which often failed to kill the adult louse. This operation was in any case useless, since only sections of a room were done at a time, and it never included the infested mattresses. Its only result was to cause the death by exposure of the less hardy prisoners ( 100 deaths on one occasion, when a party remained naked for 36 hours in the month of February).

The daily toilet of the prisoners, although in theory obligatory, was hampered by total absence of soap, a time limit of 30 seconds per person per tap, and the fact that the wash-room was also a mortuary, necessitating much manœuvring over and among corpses. The scrupulous cleansing of barrack-rooms each day did not prevent the bedding from swarming with fleas, lice, and bugs.

\section{Factors Influencing Morbidity}

As a killer, cold proved of great service to the S.S. Thus at Natzweiler, three-quarters of the Russians died after standing naked in the snow for 24 hours after a hot shower. The twicedaily roll-calls in the snow (the all-time record at Dachau was a roll-call lasting 60 hours), the snow-clearing parties, and the mecical inspections to determine fitness for work, when the candidatcs waited naked out of doors for the S.S. doctor to look at their hands (sole criterion of fitness), all helped in the work of extermination. It is unnecessary to mention the inadequacy of clothing and bedding. To the cold was added fatigue. In the closed (non-working) blocks, 16 hours a day was often spent standing outside, while in the open (working) blocks the long hours of toil and roll-calls left only four hours a night for sleep.

* An abridged translation from the French.
The overcrowding of barracks left an average of 0.5 to 0.75 cubic metre of air per man, not to mention the presence of the corpses, which remained there perhaps for a week and were sometimes reinforced at the rate of 50 per night per block. And all th s was added to a background of continuous hunger. Table I shows the food distributed in the closed blocks in a period of relative abundance-September, 1944. The calorie values may

Table I.-A Week's Rations in September, 1944

\begin{tabular}{|c|c|c|c|c|c|c|c|c|c|c|}
\hline & $\stackrel{\Xi}{\Sigma}$ & $\stackrel{\mathscr{I}}{F}$ & $\sum_{3}^{u}$ & 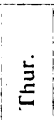 & is & $\dot{\overline{\ddot{n}}}$ & $\dot{\bar{\Delta}}$ & 䏤壱 & $\frac{\dot{n}}{\tilde{U}} \frac{\dot{s}}{\tilde{U}}$ & 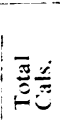 \\
\hline $\begin{array}{l}\text { Midday soup (litres) } \\
\text { Evening soup (litres) }\end{array}$ & 1 & 1 & 1 & 1 & 1 & 1 & 1 & $7 \times 150 \mathrm{~g}$. & 1 & $\begin{array}{r}1,050 \\
225\end{array}$ \\
\hline Bread (g.) .. ... & 300 & 300 & 300 & 300 & 300 & 300 & 300 & $2,100 \mathrm{~g}$. & 2 & 4,200 \\
\hline $\begin{array}{l}\text { Potatoes (g.) } \\
\text { Margarine (g.) }\end{array}$ & 150 & 150 & 150 & $\begin{array}{r}150 \\
50\end{array}$ & 150 & $\begin{array}{r}150 \\
20\end{array}$ & 150 & $\begin{array}{r}1,050 \mathrm{~g} . \\
70 \mathrm{~g} .\end{array}$ & & \\
\hline Sausage (g.) & & 50 & & & & & $\begin{array}{l}70 \\
50\end{array}$ & $120 \mathrm{~g}$. & $\frac{1}{2}$ & $\begin{array}{l}120 \\
100\end{array}$ \\
\hline $\begin{array}{l}\text { Jam } \\
\text { Sugar }\end{array}$ & & & & & & 70 & & $70 \mathrm{~g}$. & 4 & 280 \\
\hline Cheese & & & & & & & 50 & $50 \mathrm{~g}$. & 0.5 & 25 \\
\hline
\end{tabular}

Total weekly calories, 7,120 ; total daily calories, 1,017 .

seem low for individual products, but it must be remembered that, for example, the margarine had only $10 \%$ of fat, and the cheese was pure casein. The workers in the open blocks had a daily supplement of 260 to 290 calories. In March, 1945, there was a sharp drop in the rations, as shown in Table II.

TaBle II.-A Week's Rations in April, 1945

\begin{tabular}{|c|c|c|c|c|c|c|c|c|c|c|}
\hline 0 & 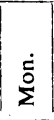 & $\stackrel{\stackrel{J}{I}}{=}$ & $\sum^{i}$ & $\stackrel{\grave{E}}{E}$ & 容 & $1 \dot{\tilde{\pi}}$ & 志 & 冚 & نे & 苛玄 \\
\hline $\begin{array}{l}\text { Midday soup (litres) } \\
\text { Evening soup (litres) } \\
\text { Bread (g.) .. }\end{array}$ & $\begin{array}{r}1 \\
1 \\
120\end{array}$ & $\begin{array}{r}1 \\
120\end{array}$ & $\begin{array}{r}1 \\
1 \\
120\end{array}$ & $\begin{array}{r}1 \\
120 \\
\end{array}$ & $\begin{array}{r}1 \\
1 \\
120\end{array}$ & $\begin{array}{r}1 \\
120\end{array}$ & $\begin{array}{r}1 \\
120\end{array}$ & $\begin{array}{l}7 \times 250 \mathrm{~g} . \\
3 \times 100 \mathrm{~g} . \\
840 \mathrm{~g} .\end{array}$ & $\begin{array}{l}1 \\
1 \\
2\end{array}$ & $\begin{array}{r}1,750 \\
300 \\
1,680\end{array}$ \\
\hline
\end{tabular}

Total weekly calories, 3,730 ; total daily calories, 533 .

\section{Medical Organization}

There were at first no doctors in concentration camps. One could either be alive and at work or dead and in the crematorium. When the Revier was first instituted medicine and surgery were practised by persons of doubtful antecedents among the inmates. In June, 1944, internee doctors were attached to blocks. They worked in open blocks, closed blocks, or the Revier. In the open blccks, the doctor collected his sick each evening and marched them over to the German Oberpfleger (head nurse) at the Revier. The Oberpfleger decided their fate. Sometimes he sent them to have a paper dressing put on their wounds; sometimes he gave them a mysterious pill and sometimes a thimbleful of wonderful elixir of life. Those with large and dirty ulcers got one to three days off work. A few rare individuals, whose axillary temperature reached $102^{\circ} \mathrm{F}$. $\left(38.9^{\circ} \mathrm{C}\right.$.), were placed in hospital. Thus the internee doctor in these blocks enjoyed a sinecure. Not so his colleague in the closed blocks. He found himself with large numbers of sick on his hands; he had to dance attendance on the German carpenter, who conducted the sick parade in the block and who amused himself by freely changing diagnoses and treatments, and he had to engage in never-ending disputes with Germans of all grades to procure the tiniest concession for his patients. For the dector working in the Revier the greatest annoyance was the German orderly, who reigned supreme there. The orderly arranged everything; the doctor was his unwelcome assistant, whose most important task was to keep a chart recording the pulse rate, the diagnosis, and the presence of any gold teeth (for reference after the patient's death). The giving of diets or drugs depended on the favour of the internee orderlies, who conducted a black market in everything.

The lack of sufficient drugs made it necessary to treat only the moderately sick, since the more serious would die anyway and the slightly sick would recover.

\section{Pathology of the Internee}

Among the many factors influencing mortality in Dachau-starvation, overcrowding, thirst, fatigue, cold, ill treatment-only the first two will be considered at length here. 


\section{(a) Starvation}

The chief dietary deficiencies were in calories, proteins, mineral salts, and vitamins. The first manifestation of starvaation was loss of weight - the disappearance of fat leading to the scaphoid abdomen and the sunken orbits of the internee ; later came muscle atrophy, the deltoids going first, then the quadriceps and the thigh adductors, so that one could introduce both fists between the adducted thighs, next the gastrocnemii, and lastly the glutei. The skin became dry, hard, wrinkled, and an earthy grey in colour. 'The hair fell out and the nails became dull, ridged, and brittle.

Parallel with the loss in weight went a progressive cardiac insufficiency. The pulse grew weaker and slower, with lowered tension and smaller amplitude. This bradycardia was interrupted by extreme and prolonged tachycardia on the slightest exertion. On screening, the heart-beats seemed of poor amplitude and the cardiac shadow enormous, clear-cut against the unusually transparent ribs. From the neuromuscular standpoint, reflexes and tonus were diminished, and the slow, clumsy movements of the patient conjured up the memory of a slowmotion film. Eventually came the stage of the living mummy, known in the camp as a "musulman."

But this state of affairs remained for a long time reversible by improved feeding, and even the extreme cases were often an "unconscionable time a-dying," while newcomers to the camp were galloping to their grave. However, the general rule was that after a loss of weight of $50 \%$ the changes became irreversible, and the "musulman" died quite suddenly, in his sleep or perhaps at roll-call. The findings at necropsy were atrophied viscera, a small, flabby heart, a pale liver, a dilated stomach with smooth mucosa, and an intestinal wall the thickness of cigarette paper.

To complicate this picture in $80 \%$ of cases there was oedema and then diarrhoea. Oedema was often the first sign of serious trouble. It appeared quite suddenly in ankles and face, and indicated a grave metabolic upset. Frequently the onset was heralded by a spell of nocturnal frequency of micturition. (Such a spell was usually followed within a week or two by oedema, by diarrhoea, or by an aggravation of general weakness.) Usually the oedema increased, involving successively the dorsum of the feet, the legs, the thighs, and the lumbar region, the soft, pale, swollen lower half of the body contrasting with the emaciated thorax and arms. There was a similarity between the face of a victim and that of a myxoedematous subject, a similarity heightened by the bradycardia, hypothermia, apathy, loss of hair, and condition of the skin. But, unlike myxoedema, this oedema pitted and was very labile. A few days of rest in bed made it disappear (with accompanying polyuria), only to reappear on exertion. Withholding fluids had no effect on it.

In time, in addition to the oedema there was pleural effusion, ascites, or acute oedema of the lung. The patient died of cardiac failure or of intercurrent infection, especially pulmonary. Cardiac insufficiency was first thought to be responsible for this oedema, but digitalis was without effect. A renal origin was negatived by the absence of urinary abnormalities and by the normal blood urea and lowered blood pressure. The oedema was apparently due to protein lack, its incidence diminishing in times of better feeding and rising sharply when rations were cut. Laboratory tests showed a lowered serum globulin, with increase in the ratio of albumin to globulin.

Diarrhoea often completed the picture of starvation. The stools were liquid, pale yellow, scarcely faeculent, increasing in frequency up to 20-30 a day, and often accompanied by a constant desire to defaecate. The patient also passed mucomembranous material. Within a couple of days his oedema disappeared and his body became skin and bone. His corpselike face, with dull cornea, dilated pupil, and wide-open mouth, and his flexed, immobile, icy body, from which came a rare superficial respiration, bore mute testimony to his misery. The end usually came within two days.

Besides these cases there was a type of primary diarrhoea (ccurring in patients still in good general condition, which swept through whole blocks, was accompanied by no other symptoms-no rise in temperature, no pathogens in the stoolsand failed to respond to all drug treatment, including emetine, sulphonamides, and pentavalent arsenicals. It was at first thought that normal saprophytic bacteria had become pathogenic. Simple dieting for 48 hours would arrest the complaint at its onset, but a relapse was easily provoked by fatigue, cold, or too speedy return to a normal diet. Cases in a later stage were irreversible and patients died in a state of collapse. This "epidemic" appeared at the same time as the increase in cases of oedema due to the cut in rations, and would seem also to have been a direct result of protein deficiency. Intravenous infusions of normal saline or of hypertonic salt solution (up to $60 \mathrm{ml}$. of $30 \%$ solution daily) given to combat dehydration were useless. After the liberation subjects were given intravenous atropine solution $(0.25-0.5 \mathrm{mg}$.) and were cured completely after three injections. A third form of diarrhoea appeared curing an epidemic of typhus at Dachau, the coexistence of these types complicating the picture considerably. Often a case which had been regarded merely as obstinate diarrhoea was found to give a positive Weil-Felix reaction. Such cases, which were regarded as an enteric form of typhus, at one time caused many deaths in Block 21 , only 300 of a total of 1,600 internees remaining alive there.

Another important manifestation of starvation was hyposlycaemia. No one ever saw an acute hypoglycaemic reaction, but in the cachetic cases many symptoms and signs (psychic disturbances, torpor, scmnolence, bradypnoea, etc.) recalled the onset of hypoglycaemic coma. The results of blood sugar and C.S.F. sugar examinations (made after the subjects were liberated) in 39 cases of psychosis with cachexia showed on the average :

Blood sugar: $58.8 \mathrm{mg}$. per $100 \mathrm{ml}$. (normal, $75-125 \mathrm{mg}$.)

Sugar in C.S.F.: $62.2 \mathrm{mg}$. (normal, $50-80 \mathrm{mg}$.).

Ratio $\frac{\text { sugar in C.S.F. }}{\text { biood sugar }}=1.095$ (normal $0.52-0.66$ ).

In acute hypoglycaemia the onset of convulsions with a blood sugar lower than $45 \mathrm{mg}$. per $100 \mathrm{ml}$. may be explained by the simultaneous fall in C.S.F. sugar to $15-25 \mathrm{mg}$., whereas in the chronic cases described here no convulsions occurred because some mechanism unknown maintained the level of sugar in the cerebrospinal fluid.

Psychic disturbances were not lacking among the internees. Apart from a general weakening of intellect, growing apathy, and melancholia, cases of hallucination and delirium occurred. In one type of psychosis the prognosis was especially bad; the patient's entire waking hours were devoted to thinking of and searching for food; when he was given his food he played with it interminably, but was incapable of swallowing the least morsel. The commonest nervous symptoms were due to a polyneuritis presumably caused by vitamin B deficiency. One patient woke in the morning with bilateral extensor paralysis of the wrists, another had peroneal palsy, and a third became suddenly completely paralysed in both legs but recovered fully after treatment with vitamin B. Nevertheless, vitamin deficiency seemed to play a very secondary part in the camp illnesses. No case of scurvy was found; osteopathies were not frequent, though dental caries was rampant. Xerophthalmia was never seen, but lack of vitamin A may have contributed to the numerous skin affections. Amenorrhoea was common in females, as was a total loss of sexual desire in the males. Azoospermia has been found in several patients since their repatriation. Skin infections of all grades, from sycosis barbae to phagedaena, were frequent. Furuncles were often seen, and were very slow in healing; carbuncles were remarkable for their extent and indolence, and the lack of accompanying fever. Giant pemphigus occurred often on the hands. Large abscesses formed and tracked along muscles and tendons, but caused little pain, no local heat, and no temperature rise: all these lesions were slow in cicatrizing.

Lung affections were common, starvation and cold both helping to produce them. Of deaths in winter $40 \%$ were due to pneumonia (case mortality $25 \%$ ). Pneumococcal empyema was a frequent complication, with a mortality of $75 \%$. The most interesting pulmonary affection was tuberculosis, $40 \%$ of necropsies showing tuberculous lesions and $15 \%$ of returned internees having some radiological evidence of the disease. Its incidence was much more closely related to diet than to overcrowding, some favoured internees in Block 16, with a dietary far above the average, being practically free from it. All the clinical types were to be seen. Acute forms appeared as 
caseating pneumonia during periods of extreme cold and as miliary tuberculosis under the spur of typhus, but the characteristic form at Dachau developed slowly, was usually bilateral, and radiologically had a floccular appearance. So slowly did it develop among the really cachectic that they did not appear to die any sooner than those with simple cachexia. Pleural effusions were very common, and some were even cured, mirabile dictu! On the whole it was surprising that not more than an average of $20 \%$ of the internees in each block died from tuberculosis.

\section{(b) Overcrowding}

In the closed blocks at Dachau 400 men occupied a room of some 200 cubic metres capacity. In such a place all the normal acts of life become a source of misery, and to the doctor who must look for, examine, and treat the many sick in this chaos the adequate exercise of his profession becomes impossible. Morbidity and mortality were seen to vary with the degree of overcrowding. (With 525 in one block, mortality was $3.4 \%$ a month; with 1,350 in it, the monthly mortality rose to $10 \%$.) An early result of overcrowding was the appearance of scabies, often with secondary infection. Erysipelas of the face was also widespread; there were frequent relapses due to poor hygiene measures, but the prognosis was fairly good. Treatment was by sulphanilamide.

The most important epidemic disease in the camp was typhus. At Dachau this disease had an average incubation period of 14 days. After a pseudo-influenzal period of invasion of 2 days the characteristic picture appeared. The diagnostic signs were: (a) intense headache, with tinnitus and deafness; $(b)$ ataxia, accompanied by a pathognomonic drunken gait; (c) a conjunctival hyperaemia, which appeared before the fever ; $(d)$ a temperature of $102-104^{\circ} \mathrm{F} .\left(38.9-40^{\circ} \mathrm{C}\right.$.), with a very rapid pulse. In addition, intense lumbago was usual. On examination a mild splenomegaly and signs of congestion at the bases of the lungs were practically constant. An interesting sign, diagnostic even in convalescents. was the appearance of rapid localized contraction on pinching the biceps. The rash, discrete and dark red, appeared on the fifth or sixth day on the trunk and the anterior aspect of the arms. This state of affairs lasted 12 to 14 days, with anorexia, photophobia, and oliguria. The temperature oscillated between $102^{\circ}$ and $104^{\circ} \mathrm{F}$. with an almost regular drop every third or fourth day. Half of the deaths were due to circulatory failure, lowered blood pressure (average 90/50) and tachycardia being usual. In patients recovering, the fall in temperature might be by crisis or by lysis. Convalescence was very prolonged, with asthenia and signs of cardiac weakness. At any stage of the illness complications might occur; these comprised three clinical types: (a) gastro-intestinal, with diarrhoea as the chief symptom ( $20 \%$ of fatal cases); (b) pulmonary, with bronchopneumonia, pleural effusion, or a miliary spread of pre-existing tuberculosis; $(c)$ nervous-the most interesting form. Apart from the headache and photophobia indicating meningeal complications, and the ataxia of cerebellar origin, other signs of involvement of the nervous system were psychic disturbances, hallucinations, delirium, convulsions, mania, opisthotonos-all of grave prognostic import and often the only features of the case apart from extremely high fever. In convalescence, even 10 to 15 days after defervescence, palsies and paraesthesiae appeared and the intellect was usually weakened. Among complications, otitis media, mastoiditis, parotitis, and phlebitis may be mentioned, but the constant myocardial involvement which left the patient incapable of effort for long periods afterwards must be particularly stressed. It was observed that the epidemic, which at first had a case mortality of $80 \%$, gradually became attenuated and finally left behind a trail of mild cases, among which even the cachectic recovered.

The western Europeans were much more severely attacked than the Slavs, and men in good condition underwent more rapid and severe forms of illness than did the cachectic. The main factor determining survival was age-the older the subject the less his chance. Although lice were universal, $20 \%$ of the inmates never showed clinical signs of the disease (? ambulant cases, ? naturally immune). Most of the patients had no treatment; the lucky few who were placed in hospital did well on intravenous glucose-saline and cardiac tonics. Towards the end of the epidemic an attempt was made to treat early cases with transfusions (200-250 ml.) of convalescent blood. The method appeared efficacious, but its correct evaluation was almost impossible.

It is unnecessary to dwell on the brutahties practised at Dachau, or on the alleged experiments carried out there, which cost the lives of hundreds of internees and were almost totally without scientific value. But it can be stated that the epidemic of typhus, which began on Dec. 17, 1944, with one case, was due entirely to the wilful negligence of the S.S. medical personnel, who encouraged its spread by distributing contacts freely about the camp.

\section{Medical Sequelae of Dachau}

Of the returned internees, $65 \%$ were found to be ill, in contrast with $7.7 \%$ of prisoners of war. Moreover, $30 \%$ were still ill in March, 1946, ten months after their liberation. The most important sequel was lung impairment, which was found in $25.8 \%$ of returned internees. Pulmonary tuberculosis occurred in $16.7 \%$. Cardiac impairment was present in 3\%, of whom onequarter died within a year. Digestive disturbances were still present in $2.1 \%$ in March, 1946, but in general were not severe. After liberation a number of internees developed gastric ulcers -an almost unknown disease at Dachau.

Avitaminoses were rare and disappeared rapidly, but cachexia and oedema were troublesome and slow to disappear, as was the tendency of the skin to infection. Almost all the internees maintained a sympathetic hyperactivity (e.g., sweating on the slightest exertion) for at least six months after their return; concentration was difficult, memory was impaired, and there was irritability and instability.

\section{JOINT TUBERCULOSIS COUNCIL}

At the last meeting of the Joint Tuberculosis Council tribute was paid to the late Dr. George Jessel, who was vice-chairman at the time of his death. Dr. James Boyd, Chief Medical Officer, Ministry of Health and Local Government of Northern Ireland, attended as observer on behalf of his Ministry, and was cordially welcomed. as observer on behalf of his Ministry, and was cordially welcomed. re-definition of terms used in tuberculosis work. The report suggested the abolition of the present system of recording cases, and suggested new classifications. New definitions of "quiescent," "arrested," and other terms were also suggested. The report was forwarded to the Minister of Health with a request that its recommendations be carried into effect.

Attention was drawn to the anomaly created by a recent ruling that where family allowances under the Government scheme are received by persons who are entitled to financial assistance under Memorandum 266/T, the 266/T allowances must be reduced by the amount of family allowance received, and the Council authorized a deputation to express to the Ministry the strong view that family allowances should have no effect upon allowances granted to tuberculous persons as such. The question of bread rationing and its effects, if any, upon tuberculous persons in and out of sanatoria was referred to the Council's committee on nutrition. Arising out of resolutions adopted at a previous meeting expressing alarm at the probable effect of the National Health Service Bill on the tuberculosis service, it was reported that a deputation representing the Joint Tuberculosis Council and the N.A.P.T. had met Sir Wilson Jameson. Sir Wilson on that occasion said that there was no intention to detach preventive work from curative work. He had also given assurances on other points. The report of the interview was accepted without prejudice to any future action which the J.T.C. might consider necessary in relation to the Bill. The standardization of the forms of record used by local authorities in connexion with their tuberculosis services was discussed, and a committee was asked to consider the present situation and, if possible, to suggest standard forms for universal use.

Arising out of a resolution of the Tuberculosis Association, the Council appointed a special committee to consider the establishment of a Bureau of Tuberculosis Statistics. The new committee was bidity statistics, to plan statistical inquiries into selected problems, and to advise-or arrange for expert advice to be afforded-on the collection of data. The committee was made as representative as possible, its membership including a tuberculosis officer, a sanatorium superintendent, a thoracic surgeon, an orthopaedic surgeon, a paediatrician; a radiologist, a bacteriologist, and a medical officer of health. The Council decided to approach the Nuffield Foundation for assistance in the project. 